\title{
Elementary School EFL Learners' Adoption of English Names and Implications for Classroom Practice
}

\author{
Grace Chin-Wen Chien \\ Department of English Instruction, National Hsinchu University of Education, Hsinchu City, Taiwan \\ Email: chinwenc@ms24.hinet.net
}

\begin{abstract}
The adoption of English names is common among elementary school English as Foreign Language (EFL) learners in Taiwan. In this study $86 \%$ of participants in this study have their own English name and 67.5\% of those who do not have one would like to. However, none of the students who have an English name know its meaning or have been told why their particular name was chosen for them. English names were mostly given to learners by English teachers at their school or a private language school. The younger the learners are, the more they feel that the adoption of an English name makes them feel like an English native speaker. Younger EFL learners also feel that having an English name makes a positive impact on their English learning and attitude. Suggestions are provided on giving EFL learners' English names and using English names as a means of cultural learning.
\end{abstract}

Index Terms - adoption of English names, identity, English learning attitude

\section{INTRODUCTION}

In Taiwan, elementary school students who have previously attended private English language institutions have their own English names, while those who haven't learned English before usually do not. On the first day of the school year, English teachers call the roll and students who do not have English names often ask the teacher to choose one for them. The majority of students who have English names do not know the meaning of their English name or the reason why they are called such a name. Some students will pick very strange names, such as Pig, Mimi, or Elephant. One girl in this study insisted on calling herself "David," no matter how many times she was told that David is a boy's name.

This study discusses English as a foreign language (EFL) young learners' adoption of English names and the relationship between English names and English learning attitude and identity. First, what is the current situation regarding elementary school EFL learners' adoption of English names? Second, what is the relationship between adopting an English name and English learning attitude? Finally, suggestions are provided on giving EFL learners' English names and using English names as a means of cultural learning.

\section{LITERATURE REVIEW}

A name defines a person and tells people who he or she is. A person's name is both literally and symbolically a part of them (Blau, 1996; Liu, 2001). A name enfolds the identity of an individual, signaling social and ideological affiliations (Chatterjee, 2003; Liu, 2001).

Scholars have studied how language learners adopt English names, why they chose the names they do, and what their attitudes toward their English names are (Chatterjee, 2003; Edwards, 2006; Wang 2009). In Edwards' (2006) study, she found that the practice of Chinese learners' adopting English names was widespread. However, none of the Chinese students interviewed in Chatterjee's study felt any anxiety about taking on English names. One teacher interviewed claimed that from the 1960s to the 1990s there was some resistance to English names, but that the current generation are eager to have an English name. For them, it is a way of 'feeling close to the local people' or to make it easier for 'native English speakers' to pronounce their names.

The majority of language learners were given an English name by their teachers (Edwards, 2006; McPherron, 2009), so Chatterjee (2003) suggests that teachers should spend some time getting the names right. Blau (1996) asked his students to write down their names, and to brainstorm lists of words, images, or feelings conjured up by their names. Blau also asked students to write stories about their names.

There are eight factors that affect how EFL learners choose their English names.

First, some of them choose to name themselves after their favorite basketball player or a famous person (Chatterjee, 2003; McPherron, 2009).

Second, students may choose their name from a dictionary (Chatterjee, 2003); this can give rise to weird and unique names (e.g. Talent, Elephant) (Wang, 2009), or to the playful creation of words (e.g. Dodo) (McPherron, 2009).

Third, students may choose names that are phonetically similar to their Chinese name, such as Lulu or Lily 
(Chatterjee, 2003; Edwards, 2006).

Fourth, students like their English names to be easy to pronounce and to remember (McPherron, 2009; Wang, 2009).

Fifth, students are concerned with the meanings, especially the literal or original meanings, of their English name (Wang, 2009).

Sixth, students choose their English names because parts of these may reflect parts of their Chinese personal name. In this study, Zelda and QQ chose their names because their Chinese names begin with Z and Q respectively. One student called himself Joe because it sounded Chinese, whilst another called himself Joe because his family name was Zhou (a very similar sound) (Edwards, 2006; McPherron, 2009).

Seventh, some students choose their names to represent how they would like to be viewed by others (Edwards, 2006; McPherron, 2009; Wang, 2009). Bonnie chose her name because it means 'beauty and intelligence'. Iris chose hers because it means rainbow goodness. Derrick chose his because it means strength.

Eighth, students may translate the concepts in their Chinese names directly into English: for example, Sky, Ocean, Summer, Apple, Tiger, Long, Sun, Moon, etc (Edwards, 2006).

Language learners hold varying attitudes toward the adoption of English names. For some Chinese students, taking on an English name was only temporary. Others cannot relate to their English names and often cannot recognize it as theirs (Chatterjee, 2003). One of the students interviewed by Chatterjee (2003) said he would continue to use his adopted 'English' name because he has had it for a long time and is known by it. Most of the students replied 'No, it's just a name. It does not mean anything" to the question 'Does adopting an English name make you feel any different?' However, one student, Lily, indicated that choosing an 'English' name gave her a sense of autonomy. She felt that renaming herself gave her a sense of being able to decide on an important aspect of her personality (Chatterjee, 2003). Furthermore, the 19 undergraduate students in China and Canada in Wang's (2009) survey regarded their English names as a kind of social investment in imagined communities of English learning or employment by a Hong Kong, Taiwanese, or foreign company in China; or even by living or working in English-speaking countries or regions. They associated their English name with their reality, such as their life goals and their ideal personal qualities.

The above studies focus on how EFL adult learners choose their English names and their attitudes toward those English names. This study aims to discuss whether EFL young learners' having English names and knowing the meanings of the names makes a difference to their English learning attitude and identity.

\section{Methods}

\section{A. Subjects}

The subjects of this study are 132 EFL middle to upper grade learners in a rural elementary school in Taiwan, consisting of 36 fourth graders, 50 fifth graders, and 46 sixth graders. Of the 132 participants, 70 are boys and 62 are girls, all of whom have received formal English education since the first grade. They have experienced three forty-minute English classes a week in the first and second grades and four forty-minute English classes in the middle and upper grades.

\section{B. Instruments}

The learners answered a questionnaire in Chinese (see Appendix I) which included 15 statements about English names. For the first ten statements, students had to choose yes/no or fill in the blank. The last five statements were measured by a 5-point Likert scale ( $1=$ strongly disagree; $5=$ strongly agree). The statements were written based on the current literature on language learners' adoption of English names and on language learning identity.

\section{Results}

The analysis is divided into two parts covering the adoption of English names and attitudes toward them.

\section{A. Current Situations of Adopting English Names}

Of the 132 participants, 86\% (114) have English names. Nineteen students could not spell their English names at all, while others spelt their names incorrectly such as "jimmy," "Danil," “andrew," "Llo," "Wilsno," "Tin,"or "gary." Of these nineteen, seven were fourth graders.

Some students picked strange or unusual names, such as Apple, Not, Bell, Mango, Nett, or Pig. One girl gave herself a boy's name: Tommy. According to Table 1, the most common boys' name is Jason, followed by Martin and Kevin. The most common girls' names are Amy and Cindy. 
TABLE 1:

POPULAR ENGLISH NAMES

\begin{tabular}{|l|l|l|l|}
\hline & Top 1 & Top 2 & Top 3 \\
\hline Boys' Names & Jason (4) & Kevin (3), Martin (3) & $\begin{array}{l}\text { Allen (2), Bruce (2) } \\
\text { Howard (2), Jack (2) } \\
\text { John (2), Sam (2) }\end{array}$ \\
\hline Girl's Names & Amy (3), Cindy (3) & $\begin{array}{l}\text { Alice (2), Emily (2) } \\
\text { Gina (2), Linda (2) } \\
\text { Lucy (2), Sandy (2) } \\
\end{array}$ & \\
& & Tina (2) & \\
\hline
\end{tabular}

Note: (Number): indicates the number of students who have this name.

The learners' English names were mostly given to them by school teachers (31\%), English teachers in private language institutes $(21 \%)$ or other family members or friends (18\%). About $15 \%$ of students adopted the English names given to them by their parents or chose them themselves. When the learners adopted their English names, none of them were told why they were given such names or the meanings of the names.

None of the students know the meanings of their English names, although more than $67.5 \%$ of the students would like to know. The younger the learners are, the more eager they are to know the meaning of their English name. Compared to only $56 \%$ of sixth graders, almost $80 \%$ of fourth graders would like to know the meaning of their English name.

Almost $83.3 \%$ of the eighteen students who did not have English names would like to have an English name. About $78 \%$ of the students who have English names would continue to use their current English names, but two students were not sure about whether they would use such names later.

\section{B. Attitudes toward the Adoption of English Names}

With regard to item 11 "Knowing the meaning of my English name motivates me to learn English well," $48 \%$ of the students totally agree or agree, whilst $37 \%$ of students remained neutral. The younger the learners are, the more they agree with such statements (see Table 2 in Appendix II for details). About $69 \%$ of the fourth graders agree or totally agree with the statement, but only $35.7 \%$ and $30 \%$ respectively of the fifth and sixth graders agreed. Students' responses to item 11 were similar to item 12 "Having an English name motivates me to learn English well." About $44 \%$ of students agree or totally agree that having an English name motivates them to learn English well. Again, the younger the learners are, the more they agree with such statements, with $69 \%$ of the fourth graders agreeing or totally agreeing with the statement but only $40 \%$ and $30 \%$ respectively of the fifth and sixth graders.

Overall, in responding to "Having an English name makes me feel like a native speaker of English, 36.8\% disagree, but another $35 \%$ of students agree as in Table 1. Fourth, fifth, and sixth graders responded differently to this statement. Almost $80 \%$ of the fourth graders felt that having English names makes them feel like native speakers of English. On the other hand, $50 \%$ of the fifth graders disagree with the statement. $56 \%$ of the sixth graders remained neutral to the statement.

Overall, $41 \%$ of students like their English teacher to call them by their English name in class, particularly the fourth graders. Almost $79 \%$ of the fourth graders prefer to be called by their English names in class. In contrast, more than half of the fifth graders dislike being called by their English names in class. Half of the students like their classmates to call them by their English names in English classes, but the other half dislike the idea. Almost $72 \%$ of the fourth graders prefer to be called by their English names in class, whereas more than $60 \%$ the fifth graders dislike being called by their English names in class.

\section{DISCUSSION}

Based on the data analysis, the following issues will be discussed in terms of EFL learners' adoption of English names, the appropriateness of the names, the learners' knowledge of the names, the relationship between English names and learners' identities, and the relationship between names and learners' attitudes.

\section{A. Wide Adoption of English Names}

The adoption of English names is common among elementary school EFL learners in Taiwan. About $86 \%$ of participants in this study have their own English names and $67.5 \%$ of those who do not have an English name would like to. The wide adoption of English among elementary EFL learners in this study is in accord with Chatterjee's (2003) finding that large numbers of Chinese ESL students have been going through a system of adopting English names.

The learners' English names were mostly given to them by English teachers in schools or private language institutes. English teachers are taking on responsibility of facilitating the teaching and learning process by encouraging the adoption of English names, and by doing so they create bridges between the learners and the target language (Chatterjee, 2003).

\section{B. Appropriateness of English Names}

A name is a noun phrase to reveal the individual reference to a person. It is a symbol that gives a person their identity. Some of the English names chosen by students in this study are not appropriate, such as Pig, Not, or Apples. One girl 
with a high English proficiency level insists on using Tommy as her English name even though the teacher explained to her that Tommy is a boy's name. Making a name one's own is an important part of individual's self-identification (Nicholaisen, 1984). Nicholaisen further argues that when a name is both given and used, it will invariably lead to recognition, which is a determinant of one's identity formation. Obviously, students who chose these inappropriate names were not aware of what native English speakers' attitude or impressions would be when they heard the names. Therefore, English teachers should guide students in choosing appropriate English names.

\section{Knowledge of English Names}

When selecting a Chinese name, Chinese people concentrate on the semantic sense, the musical sense, and the structures and meanings of the name (Liu, 2001). However, in this study, neither the parents and teachers nor the students themselves thought of the meanings of the English names when they chose them and none of the students know the meaning of their name. Liu (2001) further states that adoption of English names is a way of rebirth, implying that a new meaning has been attached to the names. Names do not only express the identity, but also the character and the ideals of the person bearing a particular name. For example, one girl in this study chooses Jolin as her English name, which makes people associate her with the well-known Taiwanese singer Jolin Tsai.

Not all the students can write their English names or spell them accurately. Some students did not capitalize their name, for example: "jimmy," "andrew," or "gary." Other students spelt their names incorrectly as "Llo," "Wilsno," or "Tin." Students should be able to write English names accurately, because one of the learning indicators under writing abilities mandated by Ministry of Education is "Be able to write your own English name" (Ministry of Education, 2001). EFL learners should be taught about the meanings and spelling of their names, so they will have better knowledge of their names, their meanings, and their identity.

\section{Relationship between English Names and Learner's Identity}

The younger the learners are, the more they feel that having an English name makes them feel like a native speaker of English; almost $80 \%$ of the fourth graders in this study feel that way. These fourth graders' concept of the adoption of English name resonates with the finding in Chatterjee's (2003) study that "adoption of English names is a way of feeling close to the local people."

The fourth graders prefer both their teacher and classmates to call them by their English names in class. Adoption of English names for the fourth graders is an identity investment that can confer a kind of symbolic capital in their target language and target culture learning (Edwards, 2006).

\section{E. Relationship between English Names and English Learning Attitude}

The younger the learners are, the more they agree that having an English name or knowing the meaning of their name motivate them to learn English well. About $69 \%$ of the fourth graders agree or totally agree with that statement, whilst only one third of the sixth graders agree with it. In McPherron's (2009) study, as adult EFL learners take more English classes in university and their English proficiency improves, they are more likely to adopt and use English names in a variety of contexts. However, the finding in this study contradicts that of McPherron's (2009) study. This study however, focuses on young EFL learners, where McPherron's study focuses on adult learners. Younger EFL learners are not afraid of losing "face" when they have to use or speak English. For them, English is a new and fun subject. Games, communicative tasks, and activities are used more in the fourth grade but as students grow older and move up to the sixth grade, they are required to memorize English words and complete more written tasks rather than just do fun games and activities. Therefore, the younger learners are more likely to feel that having an English name or knowing the meaning of their name motivates them to learn English well.

\section{IMPLICATIONS}

Chen and Chien (2007) provide seven tips for English teachers when choosing appropriate names for students.

First, it is very important that teachers should choose names that are easy to pronounce. Take the name Raul as an example. Raul originates from Spain. Generally speaking, since Taiwanese EFL learners have difficulties in pronouncing 1 and $\mathrm{r}$ sounds, the name Raul is difficult for them to pronounce.

Second, don't choose things as names, e.g. Mountain, Pencil, Apple, or Banana.

Third, avoid cute names like Bobo, Fifi, or Lala unless this is the sort of image your student wants to project.

Fourth, don't invent names such as Gindrom, or Brinty. Teachers should use names that already exist.

Fifth, when you choose names for your students, think carefully about their meaning. Some English names have roots that imply important meanings, such as jus for justice, vict for winning, Phil for love, Soph for wisdom, grace for gracefully, joy for happiness, etc. If an EFL learner describes themself as having a certain kind of personality, they may consider names with special meanings such as Justin, Victoria, Phil, Sophia, Grace, Joy or Joyce, etc.

Sixth, when choosing English names, the student's gender should be taken into consideration. Boys should choose a boy's name, for example Michael or Paul and girls should choose a girl's name such as Michelle or Polly. Some names, like McKenzie and Jamie, are acceptable for both girls and boys. Finally, teachers can help students choose English names that sound similar to their Chinese names. 
Names indicate a person's identity and English names do contain meaning. Blau (1996) recommends activities such as asking students to write down their names, brainstorming lists of words and images, and the feelings conjured by their names, reading stories and articles, and writing stories of names. Blau's recommendations mainly focus on students' names in their first language. How should English teachers introduce such concepts to their students in English classes? On the first day of the lesson, English teachers can ask students to make their own name tags. When students write down their names, the teachers can emphasize the capitalization and the correct spelling of the names.

Students can also be asked to count how many letters they have in their names or what the first letter is in their English name. English teachers can ask students to make a class graph using the amount of letters and the capital letter in each student's name. Students can title the graphs and mention what a visitor might learn from the graphs. English and math can be integrated in such an activity.

Moreover, Kevin Henkes' (1991) Chrysanthemum is a good picture book to introduce names and identity. This book is about a girl named Chrysanthemum. Chrysanthemum loves her name until she goes to school. The children laughed because her name was so long and she was named after a flower. The teasing continued until they discovered the name of their favorite music teacher!

Several questions can be asked after reading the picture books, such as: (1) How did Chrysanthemum feel about her name in the beginning of the book? (2) What happened that changed how she felt about her name? (3) How would it make you feel if someone teased you about your name? (4) What did Mrs. Twinkle think about Chrysanthemum's name? or (5) Do you have a favorite doll or stuffed animal? What is its name? Why did you choose this name?

English teachers can provide the names of online websites and ask students to research the meanings and origins of their names. English teachers can provide students with sentence strips, so they can introduce themselves by saying, "My English name is __. It means __. The name is from ___(language)." Taking the most common boy's name among the participants in this study "Jason" as an example, a boy named Jason can say, "My name is Jason. Jason means 'healer.' It is from Greek." For students with higher proficiency levels, they can be asked to read the stories and myths about their names.

Chatterjee (2003) claims that EFL teachers can create bridges between the learners and the target languages. In the process of doing this, EFL teachers go through levels of cross-cultural awareness. Through the introduction of awareness and knowledge of adoption and meanings of English names, students will be able to raise their general cultural awareness of English names. Through the study of names historically and phonologically, students will be able to learn the social and natural environment, social development and political background of the time and culture (Liu, 2001).

\section{CONCLUSIONS}

The adoption of English names is common among elementary school EFL learners in Taiwan. In this study $86 \%$ of participants in this study have their own English name and $67.5 \%$ of those who do not have one would like to. However, none of the students who have an English name know its meaning or have been told why their particular name was chosen for them. English names were mostly given to learners by English teachers at their school or a private language school. The younger the learners are, the more they feel that the adoption of an English name makes them feel like an English native speaker. Younger EFL learners also feel that having an English name makes a positive impact on their English learning and attitude.

This study focuses on elementary school EFL learners' attitudes toward the adoption of English names. Students responded that their English names were chosen by their English teachers in school or private language institutes. A follow-up study could focus on elementary school teachers' perspectives of EFL learners' adoption of English names and their classroom practice regarding the teaching and selection of English names.

APPENDIX I: QUESTIONNAIRE

1. I have an English name. $\quad \square$ Yes $\square$ No

2. My English name is

3. I don't have an English name, but I want to have an English name. $\square$ Yes $\square$ No

4. I know the meanings of my English name. $\quad \square$ Yes $\square$ No

5. The meanings of my English name is

6. The person who gave me this name is .
$\square$ My parents
$\square$ Teachers in language schools
$\square$ Teachers in my school

$\square$ Myself

7. The person who gave me this name told me the meaning of my English name. $\square$ Yes $\square$ No

8. The person who gave me this name told me why he/she gave me this name.

$\square$ Yes $\square$ No

9. I want to know the meaning of my name.

10. I will continue to use this English name. 
Read the following five statements and choose 1-5.

$\square 1$ total disagree $\square 2$ disagree $\square 3$ OK $\square 4$ agree $\square 5$ total disagree Statements

11. Knowing the meanings of my English name motivates me to learn English well.

12. Having an English name motivates me to learn English well.

13. Having an English name makes me feel like a native speaker of English.

14. I feel good when my English teacher calls my English name in class.

15. I feel good when my classmates call my English name in class.

\section{REFERENCES}

[1] Blau, S. (1996). What's in a name? Paper Presented at the 47th Annual Meeting of the Conference on College Composition and Communication, Milwaukee, Wisconsin.

[2] Chatterjee, M. (2003). Renaming: Class acts of colonization or global best practice. Presented at the 16th Educational Conference Melbourne.

[3] Chen, C. L. \& Chien, C.W. (2007). What's in an English name? The practice of adopting English names of Taiwanese English learners. Paper presented at the Sixteenth International Symposium and Book Fair on English Teaching, Taipei, Taiwan.

[4] Edwards, R. (2006). What's in a name? Chinese learners and the practice of Adopting 'English' names. Language, Culture, and Curriculum, 19(1), 90-103.

[5] Hoffman, E. (1989). Lost in Translation. A life in a new language. New York, NY: Dutton.

[6] Liu, Y. Z. (2001). Names: The mirror of the society. Paper presented at the annual Massachusetts State College Graduate Research Symposium.

[7] McPherron, P. (2009). "My name is Money": Name choices and global identifications at a South-Chinese university. Asia Pacific Journal of Education, 29(4), 521-536.

[8] Ministry of Education (2001). Guidelines on English teaching activity designs and assessments in elementary and junior high school. Taipei, Taiwan: Author.

[9] Nicolaïsen, W.F.H. (1984). Name and narratives. The Journal of American Folklore, 97(385), 259-272.

[10] Wang, P. (2009). Chinese students' English name practices and their identities. (Unpublished master's thesis). McGill University, Canada.

Grace Chin-Wen Chien graduated from the University of Washington with a doctorate in education in June 2011. She works as an elementary school English teacher and teacher-trainer in Taiwan. Her research interests are language education, language teachers' education, and curriculum and instruction. 